
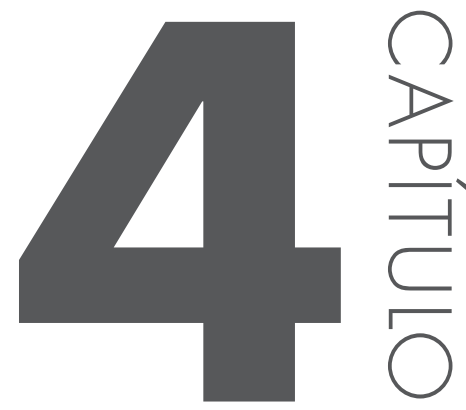

\title{
PROPOSTA METODOLÓGICA PARA ANÁLISE DA INFLUÊNCIA DOS FATORES GEOGRÁFICOS NAS VARIAÇÕES CLIMÁTICAS EM PEQUENAS CIDADES: O EXEMPLO LAGOA FORMOSA (MG)
}

de Siqueira Castro, Francielle ${ }^{1 *}$; Aparecido Costa, Rildo 2

' Mestranda do Programa de Pós-graduação em Geografia da Universidade Federal de Goiás/Regional Catalão e Bolsista CAPES

2 Docente do Curso de Geografia da Universidade Federal de Uberlândia/ Campus Pontal e Professor convidado do Programa de Pós-graduação em Geografia da Universidade Federal de Goiás/Regional Catalão

* e-mail: franciellesiqueiracastro@gmail.com

\section{RESUMO}

Este trabalho teve por objetivo apresentar uma proposição metodológica em busca do entendimento do processo de atuação dos fatores geográficos no clima urbano em pequenas cidades, tendo como exemplo a cidade de Lagoa Formosa (MG). Para tanto foi utilizado de embasamentos bibliográficos que retratam a temática, clima urbano. O Sistema Clima Urbano de Monteiro (1971), foi a base para a proposição metodológica apresentada. Foi utilizado o modelo de transectos móveis, que consiste na demarcação e coleta de dados de temperatura e humidade do ar em pontos espalhados pelo sítio urbano, de forma abarcar, também, os espaços intraurbanos. Os dados foram coletados, 
tabulados e especializados em forma de cartogramas de isovalores, apresentando a realidade térmica do recorte de estudo. É preciso ficar claro que esta é uma de muitas metodologias para análise do clima urbano. Por se tratar de uma pesquisa em andamento ainda não é possível apresentar dados concretos sobre a estrutura termohigrométrica do referido recorte de estudo.

Palavras-chave: Clima urbano; Proposição metodológica; Lagoa Formosa (MG) 


\section{INTRODUC̣ÃO}

Atualmente as alterações climáticas têm ganhado visibilidade diante dos membros da comunidade científica, ambientalista, política entre outras, na busca de discussões para minimização de impactos gerados pela atuação do homem no ambiente, principalmente em áreas urbanas. $O$ reflexo da influência antrópica sobre o espaço urbanizado traduz-se em diversos fenômenos ambientais urbanos como ilha de calor, efeito estufa, poluição atmosférica, inversão térmica, impermeabilização do solo. Estes se configuram como um dos fatores que garantem, com maior frequência, impactos às cidades, provocados através das alterações, tanto na temperatura e umidade relativa do ar, quanto na vegetação, resultando em um desconforto ambiental, o que implica na qualidade de vida da população.

As discussões sobre corruções climáticas tem sido foco, não apenas no âmbito das metrópoles, mas também em cidades ditas médias ou de pequeno porte, visto que é no meio humanizado que aflora uma gama de condições desfavoráveis à qualidade de vida e à falta de manejo ambiental ou de soluções alternativas, o que desencadeia sérias consequências ao meio natural, exigindo ações reparadoras no âmbito do poder público a fim de reduzir os impactos provocados pelo homem que, no afã de ampliar seus lucros financeiros, agridem e degradam a natureza. Tomando como base as análises e interpretações de estudos em climatologia geográfica urbana, percebe-se que o universo citadino está amplamente aberto ao que há de mais interdisciplinar, e isso vem de encontro ao fato de as cidades terem se tornado cada vez mais a morada do homem e constitui-se, portanto, em um lugar onde se produz economicamente, onde centralizam serviços, negócios, pessoas, automóveis, edificações.

A “expulsão" da população do meio rural, o consequente aumento da urbanização e a intensa ação antrópica sobre o meio físico, são alguns dos fatores que favorecem as modificações na estrutura urbana até então vivenciada. Espaços considerados impróprios para aglomerações são ocupados e ainda, espaços antes desocupados são utilizados para construção de novos loteamentos e, por consequência, acarretam na ampliação da área impermeabilizada provocando, assim, outros impactos ao ambiente.

Este artigo tem por objetivo apresentar uma proposição metodológica em busca do entendimento do processo de atuação dos fatores geográficos no clima urbano em pequenas cidades, tendo como exemplo a cidade de Lagoa Formosa (MG). Para tanto, será considerado a estrutura térmica e umidade relativa na cidade e seu entorno.

O mesmo se justifica pela inserção do clima urbano em um sistema 
onde consegue importar energia através do seu ambiente, sendo assim, palco de uma sucessão de eventos que articulam diferenças de estados, mudanças e transformações internas que se enquadram na categoria dos "sistemas abertos". Estes eventos variam de acordo com o uso do solo e as características geoecológicas do lugar, o que leva a busca pela compreensão da paisagem e de suas estruturas de forma detalhada e isso contribui para sua interpretação.

Para o desenvolvimento deste artigo foram selecionados alguns trabalhos tidos como referências indispensáveis nos estudos de clima urbano, para que assim pudessem ser apontadas algumas metodologias. Para os estudos buscamos nomes como: Drew (2011), Mendonça (1994, 2001 e 2003), Monteiro (1975), Sant'anna Neto (2008) entre outros.

Cabe destacar que a pesquisa está em andamento e, por esse motivo, ainda não é possível apresentar dados concretos sobre a estrutura termohigrométrica do referido recorte de estudo.

\section{LOCALIZAC̣ÃO E CARACTERIZAC̣ÃO DA ÁREA DE ESTUDO}

O recorte espacial do trabalho trata-se do município de Lagoa Formosa, localizado na Mesorregião Geográfica do Triângulo Mineiro e Alto Paranaíba, situado entre as coordenadas geográficas de $18^{\circ} 46^{\prime} 44^{\prime \prime} \mathrm{S}$ e $46^{\circ} 24^{\prime} 28^{\prime \prime} \mathrm{O}$ (Figura1).

Geograficamente o município está situado a aproximadamente $456 \mathrm{~km}$ da capital do país - Brasília, 374 km da capital do estado de Minas Gerais, Belo Horizonte e $233 \mathrm{~km}$ de Uberlândia, cidade de destaque no cenário econômico da Mesorregião.

Do ponto de vista dos aspectos físicos o local possui o clima caracterizado como tropical, com verão quente e úmido. O inverno é seco, com temperaturas amenas, estas características muitas vezes associadas à altitude que é de, aproximadamente, 902 m, se encaixando na classificação climática de KöppenGeiger como Aw, ou seja, um clima tropical, com inverno seco, de maio a outubro e estação chuvosa no verão, de novembro a abril. A temperatura média do mês mais frio é superior a $18^{\circ} \mathrm{C}$. As precipitações são superiores a $750 \mathrm{~mm}$ anuais, podendo atingir níveis de até $1800 \mathrm{~mm}$. Esse tipo de clima predomina principalmente na parte oeste do Triângulo Mineiro, praticamente toda a metade norte de Minas Gerais e no sudeste de Minas. A vegetação do município tem predomínio de matas, cerrados, campos e áreas de cultivo (FONSECA, 2006). 


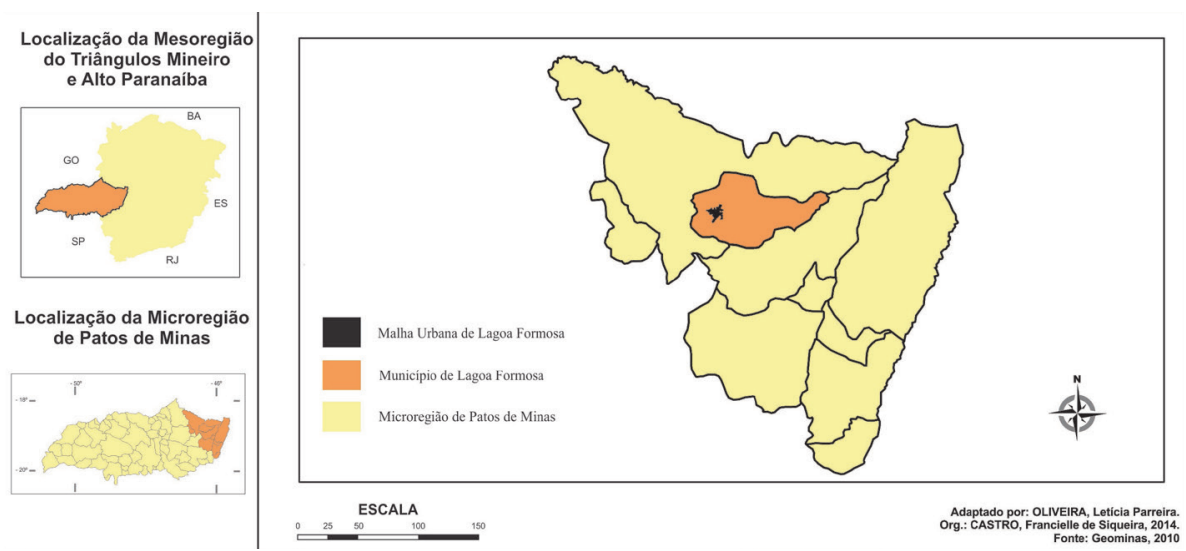

Figura 1- Localização do município de Lagoa Formosa (MG), 2013.

Fonte: Geominas, 2010. Org: CASTRO, F.S. 2013.

Os aspectos demográficos apontam que sua população atingiu em 2010, segundo dados do Instituto Brasileiro de Geografia e Estatística (IBGE), 17.161 habitantes e a estimativa para 2013 foi que a população saltasse para 17.885 moradores, com esses valores, dentro das definições adotadas pelo IBGE (2010) o município se enquadra como de pequeno porte em que: "municípios de pequeno porte 1 - até 20.000 hab.; municípios de pequeno porte 2 - de 20.001 até 50.000 hab.; município de médio porte - de 50.001 até 100.000 hab. e município de grande porte: de 100.001 até 900.000 hab". Desse total, uma quantidade significativa encontra-se na área urbana, chegando a aproximadamente $75 \%$ de taxa de urbanização, distribuída em uma área total de aproximadamente $844,539 \mathrm{~km}^{2}$ (Tabela 1 ).

Tabela 1 - Lagoa Formosa-MG: população total/rural/urbana e taxa de urbanização - 1991, 2000 e 2010.

\begin{tabular}{|c|c|c|c|c|c|c|}
\hline & $\begin{array}{l}\text { POPULACÃA } \\
\text { (1991) }\end{array}$ & $\begin{array}{l}\text { \% DO TOTAL } \\
\text { (1991) }\end{array}$ & $\begin{array}{l}\text { POPULACC̃̃O } \\
(2000)\end{array}$ & $\begin{array}{l}\text { \% DO TOTAL } \\
(2000)\end{array}$ & $\begin{array}{l}\text { POPULACC̃̃O } \\
(2010)\end{array}$ & $\begin{array}{l}\text { \% DO TOTAL } \\
(2010)\end{array}$ \\
\hline $\begin{array}{l}\text { POPULACÃO } \\
\text { TOTAL }\end{array}$ & 15.949 & 100 & 16.293 & 100 & 17.161 & 100 \\
\hline URBANA & 8.630 & 54,11 & 10.848 & 66,58 & 12.967 & 75,56 \\
\hline RURAL & 7.319 & 45,89 & 5.445 & 33,42 & 4.194 & 24,44 \\
\hline $\begin{array}{l}\text { TAXA DE } \\
\text { URBANIZAC̄ÃO }\end{array}$ & . & 54,11 & . & 66,58 & - & 75,56 \\
\hline
\end{tabular}

Fonte: Atlas Brasil, 2013. Org.: CASTRO, F. S. 2013. 
A economia da cidade se baseia na agropecuária, no comércio e na prestação de serviços. Conta com pequenas empresas comerciais e industriais, destacando-se principalmente na agricultura com produtos como feijão, milho, mandioca, café, leite entre outros. (Tabela 2).

Tabela 2 - Produto Interno Bruto por Setor da Economia - Lagoa Formosa, Minas Gerais e Brasil, 2013.

\begin{tabular}{lccc}
\hline & LAGOA FORMOSA & MINAS GERAIS & BRASIL \\
\hline AGROPECUÁRIA & 85.285 & 15.568 .048 & 105.163 .000 \\
\hline INDÚSTRIA & 11.036 & 54.306 .183 & 539.315 .998 \\
\hline SERVIC̣OS & 83.817 & 97.398 .820 & 1.197 .774 .001 \\
\hline
\end{tabular}

Fonte: Instituto Brasileiro de Geografia e Estatística - IBGE 2013. Org.: CASTRO, F.S. 2013.

Os Índices de Desenvolvimento Humano (IDH) apontados pelo Atlas Brasil assinalam que o município, em 1991, possuía um índice que girava em torno de 0,689. Já nos anos 2000, percebeu-se um aumento e uma consequente melhoria para 0,750 e, na última avaliação no ano de 2010, o índice baixou para 0,703 .

Com a expansão e a reconfiguração do espaço urbano, via processo de urbanização, alguns locais ganharam novas formas e, é neste contexto que se pauta o estudo. A cidade passa de predominantemente rural para urbana, e isso faz com que novas configurações apareçam em seus aspectos climáticos.

Cabe aqui ressaltar que, por se tratar de um município mineiro de pequeno porte, poucos estudos foram desenvolvidos acerca de suas características físicas geográficas. Justifica-se, assim, a importância de estudos desse tipo no que tange o município em questão, ressaltando a importância para futuros estudos na área.

\section{ESTUDOS CLIMÁTICOS URBANOS E SEUS IMPACTOS NO AMBIENTE, SOB O OLHAR DAS PEQUENAS CIDADES}

O desenvolvimento significativo do setor industrial em meados do século XX foi um dos motivos pelo qual o campo brasileiro começa a perder visibilidade perante aos centros urbanos que se intensificaram, um processo que proporciona 
uma nova caracterização da divisão territorial do trabalho, na qual o modelo urbano-industrial começa a ser tomado como ponto central. As transformações que ocorreram são resultados da inserção do país no processo de globalização e culminaram, com a integração nacional, no resultado manifestado na formação e ampliação de uma rede urbana nacional.

Diante deste contexto, grande parte das áreas pertencentes ao Cerrado, no Brasil, passou a se organizar no modelo agrícola moderno e, então, após os anos de 1970 a "antiga" estrutura da fazenda autossuficiente perde significado para as atuais dinâmicas que envolvem as relações tipicamente capitalistas. Assim, os vínculos com a indústria, com a agroindústria e com o capital financeiro se tornam intensos. E é nessa mesma conjuntura que se iniciam os fenômenos de descentralização industrial e da modernização agrícola, os quais além de promover mudanças no padrão da divisão territorial do trabalho, favoreceram o crescimento das cidades, especificamente as pequenas e médias cidades, modificando para a atual rede urbana brasileira.

Os municípios de pequeno e médio porte começam a ganhar mais visibilidade no sistema urbano brasileiro entre os períodos 1970 a 1990, tendo a maioria intrínseca relação com o campo (SILVA e SOARES 2010).. Com o processo de globalização, observa-se que as relações entre as cidades vêm se tornando cada vez mais complexas, tendo essas atraído investidores nacionais devido às instalações que movimentaram o comércio local, enquanto os centros metropolitanos tendem a produzir serviços especializados e gerenciais. As pequenas e médias cidades tem se tornado verdadeiras fronteiras entre processos rurais e urbanos, junto aos movimentos acumulativos próprios da contemporaneidade.

Portanto essas cidades constituem-se em grandes desafios para a pesquisa em Geografia no Brasil por diversos motivos. Um deles é a difícil aquisição de produções acadêmicas significativas sobre essa temática, mas há de ser levado em consideração que a urbanização brasileira também é algo novo no cenário brasileiro se comparado aos demais países europeus ou mesmo americanos. Todavia, os estudos relacionados a essa temática, os recortes demográficos, classificação ou mesma a definição de pequena cidade são complexos e necessitam de atenção especial com um capítulo à parte a ser discutido.

Diante destes apontamentos fica clara a importância de estudos voltados ao entendimento das pequenas cidades, visto que esses trabalhos possibilitarão não só aumento das discussões bibliográficas do assunto, como, também, contribuirão para o planejamento, tanto o intraurbano quanto o interurbano. Com a criação de ações junto aos municípios acarreta-se a possibilidade de avaliação das potencialidades locais e suas fragilidades e, assim, diretrizes, 
prioridades e estratégias poderão ser criadas a fim de se alcançar os objetivos definidos em médio e longo prazo. Diante desses pressupostos será trazido na sequência, discussões sobre a relevância dos estudos climáticos na dinâmica geográfica urbana.

Nos últimos anos a população urbana se multiplicou com velocidade e ocupou os mais inimagináveis espaços nas áreas urbanas se adaptando com facilidade às condições a ele delimitadas: climáticas, topográficas, espaciais, sociais dentre outras. Nessa perspectiva Santos (1996, p. 37) diz que há um espaço habitado "segundo um ponto de vista biológico, pelo reconhecimento da adaptabilidade do homem como indivíduo, às mais diversas altitudes e latitudes, aos climas mais diversos, às condições naturais mais extremas".

Esse espaço, apontado por Santos (1996) e suas alterações, principalmente no que diz respeito às condições climáticas, tem sido foco de estudos. As preocupações com as alterações atmosféricas da cidade e de seus arredores têm sido tratadas antes mesmo da revolução industrial e, com seu desenvolvimento, as preocupações se tornaram mais evidentes, o que despertou para os primeiros estudos do clima urbano. Porém, foram nas últimas três décadas (1980-2009) que o homem passou a observar, de forma mais atuante, as mudanças sensíveis nas escalas microclimáticas e mesoclimáticas. Com as variações no clima nas últimas décadas, observa-se marcantes alterações no ritmo climático, como secas intensas, chuvas calamitosas. Estes fenômenos atmosféricos conhecidos hoje como "eventos extremos" fazem parte dos "desvios" em relação à média e, esses desvios, participam do quadro "habitual” do clima. Na concepção de Monteiro (1991),

[...] a ideia do negativo e do desfavorável ou maléfico dos eventos naturais extremos ou acidentais merece [...] outra reflexão [...] Um impacto pluvial calamitoso desabado sobre uma cidade poderá, apesar dos negativos, ter contribuído para despoluir uma atmosfera local gravemente afetada [...] Isto, evidentemente depende da intensidade do impacto, geralmente tanto mais "negativo"- grifos do autor- quanto mais forte. (MONTEIRO, 1991, p.12-13).

No Brasil os estudos sobre o clima urbano ganhou destaque a partir da década de 1960 quando os problemas ambientais, como poluição do ar e inundações, se tornaram mais intensas, principalmente nas grandes metrópoles como São Paulo e Rio de Janeiro. Este fato colaborou para que estudiosos da área se preocupassem em expandir as pesquisas no cenário brasileiro, sobre as alterações climáticas. 
Monteiro (1975), em sua tese “Teoria e Clima Urbano”, apresenta-se como um dos incentivadores na área do clima urbano. Buscou novas abordagens metodológicas para o estudo e fez associações entre os elementos do SCU Sistema Clima Urbano (ação ecológica natural, fenômeno da urbanização). Assim, o ambiente natural não é desvinculado do social. Com essa concepção, ele define o clima urbano como "um 'Sistema Singular', abrangendo um fato natural (clima local) e um fato social (a cidade), - grifos do autor - analisado através de canais de percepção humana.” (GONÇALVES, 2003, p. 77).

Para que o entendimento das alterações nos fatores climáticos seja elucidado, vê-se a necessidade de conhecer, também, os conceitos de clima na visão de diferentes autores Cabe lembrar que essas definições são aperfeiçoadas de acordo com as transformações no espaço-tempo, de forma que retrate melhor a realidade de estudo.

Hann (1884 apud MONTEIRO, 1975, p. 6) define clima como “o conjunto dos fenômenos meteorológicos que caracterizam a condição média da atmosfera sobre cada lugar da Terra". As carências dessa definição se encontram, primeiramente, por corresponder a uma média destituída de realidade para caracterizar os elementos do clima e, em segundo lugar, por apresentar caráter estático, artificial, não mencionando o desenvolvimento dos fenômenos no tempo, o que certamente não se aplica às atuações climáticas, visto que, os estudos não devem se atentar à média e, sim, aos eventos ocasionais marcantes dentro de um período muitas vezes não revelado nas médias e, ainda, o clima deve ser visto como um fator em constante movimento.

Levantamentos pautados em discussões sobre a climatologia apontam que o melhor conceito aplicado ao real caráter dinâmico do clima é o de Sorre (1934 apud TARIFA, 2001, p.12), propõe que "o clima é a série de estados atmosféricos acima de um lugar em sua sucessão habitual". Nessa perspectiva é sugerido um novo modelo aos estudos climáticos: substitui-se a média pelo ritmo. Isso faz com que a sucessão dos estados atmosféricos (tipos de tempo) seja observada por meio da interação dos elementos climáticos associado à circulação atmosférica. Conti (1996) sugere que não se faz necessária aquisição e análise de períodos longos de observações de registros climáticos para alcançar um resultado, às vezes apenas uma avaliação de uma dada estação do ano é suficiente para análise e obtenção de resultados satisfatórios na explicação de determinados fenômenos. Isso dependerá do objetivo proposto junto à realização das análises. Sobre esta questão, Monteiro (1971, apud MENDONÇA, 2001, p.21) descreve que, 
[...] o ritmo climático só poderá ser compreendido através da representação concomitante dos elementos fundamentais do clima em unidades de tempo cronológico pelo menos diária, compatíveis com a representação da circulação atmosférica regional, geradora dos estados atmosféricos que se sucedem e constituem o fundamento do ritmo.

Ainda sobre o ritmo, Monteiro (1971, apud SANT'ANA NETO, 2008, p. 69) expõe claramente a importância do encadeamento dos tipos de tempo, nos seguintes termos:

[...] somente o fundamento do ritmo, analisado a partir do encadeamento dos tipos de tempo, portanto, na escala diária, seria a única estratégia possível de conciliar a compreensão dos mecanismos atmosféricos com as possibilidades de entendimento do papel do clima como fenômeno geográfico e, portanto, de interferência nas atividades humanas na organização do espaço. Estas idéias pressupõem um caráter qualitativo, mas que possibilita uma analogia com os diversos elementos do espaço geográfico.

Esta interligação entre a dinâmica encontrada junto aos elementos geográficos leva o autor a propor uma outra questão:

Só a análise rítmica detalhada ao nível de 'tempo', revelando a gênese dos fenômenos climáticos pela interação dos elementos e fatores, dentro de uma realidade regional, é capaz de oferecer parâmetros válidos à consideração dos diferentes e variados problemas geográficos desta região. (MONTEIRO, 1971 apud CUNHA \& VECCHIA, 2007, p. 144-145).

A avaliação das condições climáticas é dada através da combinação de eventos naturais e culturais como clima-vegetação, clima-vegetação-solo, clima-vegetação-solo-atividade humana. Dessa forma, devem-se observar dois aspectos: a escala (micro, meso ou macro regional) e o conjunto de fatores e elementos climáticos existentes no espaço geográfico, pois se sabe que as alterações climáticas acarretam situações diferentes dependendo do local interferido pela dinâmica das escalas superiores e pelos aspectos ambientais, uma vez que o meio geográfico varia no espaço e no tempo, assim como, a dinâmica de sua escala. Neste sentido Ribeiro (1993) aponta que: 
O clima é regido por um conjunto integrado de fenômenos que se fundem no tempo e no espaço, revelando uma unidade ou tipo passíveis de serem medidos em seu tamanho (extensão) e em seu ritmo (duração). [...] A cada nível escalar deve corresponder uma abordagem específica, no sentido da coerência entre extensão e duração do fenômeno climático com as técnicas analíticas, desde a obtenção dos dados, passando pelo seu tratamento estatístico - matemático, até a sua apresentação gráfica e cartográfica (RIBEIRO, 1993, p. 288).

No caso das alterações climáticas desenvolvidas na escala de análise das cidades ressalta-se que devem ser ligados a essas variáveis fatores que contribuem para diferenciações climáticas dentro desse espaço (qualidade do material utilizado nas construções, arranjo do arruamento, rugosidade, asfalto, pouca ou nenhum espaço verde) e ao desenho urbano que não é, na maioria das vezes, adaptado ao tipo de clima da região. Essas diferenciações criam microclimas dentro da cidade pelo desempenho térmico de acordo com as várias formas de uso e ocupação do solo. É o que Chandler (1962, apud VIDAL, 1991, p. 31) chama de "coleção de microclimas".

Cabe ressaltar, neste ponto, que a noção de escala em climatologia facilita a escolha das categorias climáticas a partir do momento que se tem em mente os objetivos do estudo e a natureza das informações dispostas. Há, portanto, a necessidade de hierarquização das ordens de grandeza, pois a partir do momento que se caminha em direção a unidades menores o número de variáveis tornase significativamente maior. Da mesma forma, à medida que reduzimos as unidades espaciais sujeitas às análises, as velocidades das mudanças temporais, também, se alteram. Trata-se de usar o tipo de escala de acordo com a realidade da pesquisa, fontes e dados necessários face aos resultados que se pretende alcançar.

A partir, das discussões realizadas é preciso destacar que as alterações no clima não estão presentes apenas na paisagem urbanística, mas em todo quadro geoecológico, através de tudo que leva o homem a desenvolver-se economicamente. Implica-se, assim, em um processo de transformação e produção. Com isso ocorre a necessidade de adotar atitudes bem pensadas e planejadas para instalação de indústrias poluidoras como a petroquímica, fato complexo, pois o homem, como afirma Monteiro (2003, p. 38), “[...] antes de degradar o ambiente natural, muitas sociedades humanas, em suas relações econômicas e mesmo sociais, degradam o próprio homem, o que reflete, sobretudo na cidade.” 
Diante do exposto, é possível afirmar que nenhuma cidade, seja de pequena a grande porte, está imune às consequências provocadas pela ação antrópica, que reconfigura o espaço urbano e as variações climáticas e exige estratégias capazes de manter um equilíbrio entre o ambiente natural e o artificial.

De modo recente as médias e pequenas cidades começaram a despertar o interesse pelos pesquisadores no que diz respeito aos estudos do ambiente climático, embora, ainda se observe carência bibliográfica quanto à temática ligada a tal estudo, “[...] fato que eleva o arcabouço de conceitos produzidos até o presente, a uma dimensão de alta relatividade, pois, os que foram produzidos leva em conta, sobretudo, aglomerações urbanas de grande porte e metropolitanas" como afirma Mendonça (2003, p.96). Neste estudo, ao relatar as diferentes características presentes entre as cidades de grande porte, metropolitanas e de porte médio/pequeno destaca que a última apresenta "[...] consideráveis facilidades para a identificação de suas paisagens intraurbanas; estas, previamente identificadas, permitirão uma melhor compreensão da interação sociedade-natureza na construção do clima urbano.” Mendonça (2003, p.96).

E é nessa configuração que se pauta a pesquisa. É através do entendimento da dinâmica intraurbana que haverá a possibilidade da análise da influência dos fatores geográficos na dinâmica climática na cidade de Lagoa Formosa (MG).

\section{O SISTEMA CLIMA URBANO (SCU): UMA PROPOSIÇÃO METODOLÓGICA PARA ANÁLISES CLIMÁTICÁS EM PEQUENAS CIDADES - O EXEMPLO LAGOA FORMOSA (MG)}

Sabemos que é na etapa metodológica que o pesquisador delimita onde e como será desenvolvida a pesquisa e, ainda, indica como e quais ferramentas serão utilizadas para se chegar às respostas. Para tanto, os resultados satisfatórios só serão possíveis com a intercalação das pesquisas teórica, documental e de campo, que darão sustentação nas discussões empíricas e base para os resultados alcançados durante todo o trabalho.

A proposição metodológica fundamenta-se em teorias propostas no SCU, desenvolvido por Monteiro (1975), iniciador das construções teóricometodológico do estudo sobre o clima urbano de cidades de porte médio e pequeno. No SCU, as interações entre a atmosfera e a cidade são analisadas por meio de três canais de percepção humana: $1^{\circ}$ - denominado de "conforto térmico" está relacionado ao subsistema termodinâmico, notadamente quanto 
às ilhas de calor/frescor que se manifestam sobre o espaço urbano; $2^{\circ}$ - chamado de "qualidade do ar" é referente ao subsistema físico-químico, que consiste no estudo da poluição e de suas implicações para a cidade e seus habitantes; e o $3^{\circ}$ é o do "impacto meteórico", que trata do subsistema hidromecânico, cujo foco está nas questões ligadas às inundações, aos movimentos de massa (por exemplo, escorregamentos) e a outros problemas provocados pela precipitação pluvial e seu escoamento sobre a superfície da cidade.

O presente trabalho vinculará ao primeiro canal (conforto térmico, subsistema termodinâmico) e, baseando-se nesta proposta, Mendonça (2003) elaborou um roteiro como base metodológica em quatro fases, às quais também serão seguidas para desenvolvimento desta pesquisa, sendo elas: demarcação do campo de análise e do subsistema climático a ser estudado (termodinâmico, impactos hidrometeóricos e físico-químico); fundamentação cartográfica; setorização da cidade em ambientes geográficos diferenciados (análise espacial); levantamento das características climáticas dentro de uma abordagem genética; definição dos pontos de amostragens e periodicidade da coleta de dados em campo; realização de trabalho de campo - mensuração dos elementos climáticos em diferentes momentos do dia (escala horária), dos meses e do ano e definição e análise das características específicas do clima urbano estudado, formulando sugestões na perspectiva do desenvolvimento e planejamento da cidade.

Em suma, propõe-se um trabalho sob a perspectiva do método de transectos móveis, que consiste na demarcação de pontos espalhados pelo sítio urbano, de forma a abarcar, também, os espaços intraurbanos. Para a cidade de Lagoa Formosa foram escolhidos 9 pontos distribuídos por toda extensão da cidade (Imagem 1).

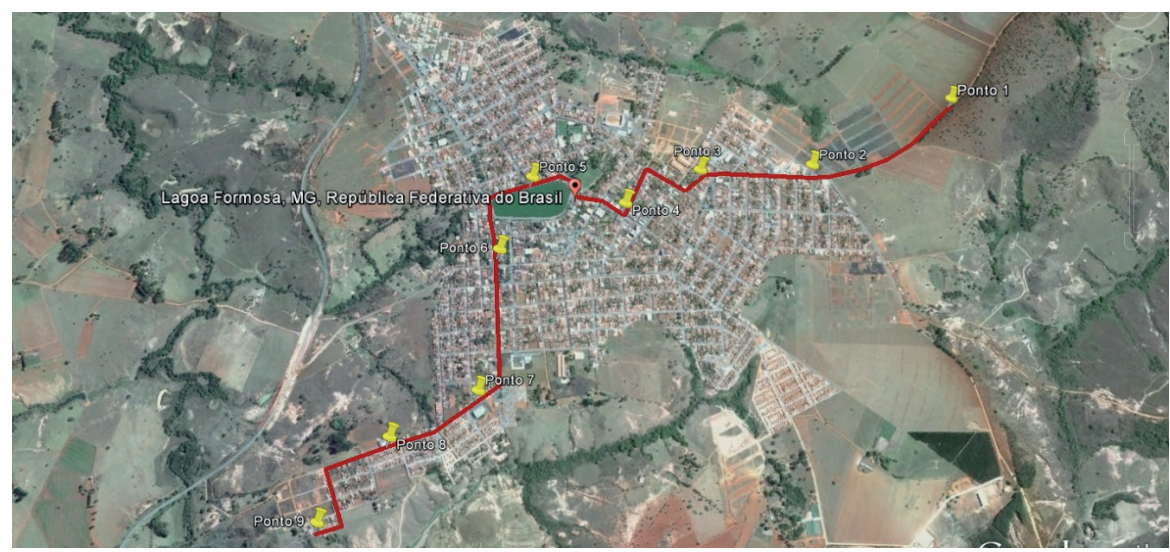

Imagem 1 - Lagoa Formosa (MG): localização dos pontos de coleta de dados, 2014.

Fonte: Google Earth, 2014 
Os dados são adquiridos por aparelhos climatológicos, dos quais se sugere data logger; termo-higrômetro digital portátil; termo-anemômetro digital e um GPS - com bússola - (Figura 2) com coletas durante 10 dias no inverno e 10 dias no verão, nos períodos de 09:00, 15:00 e 21:00 horas.

1)

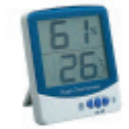

2)

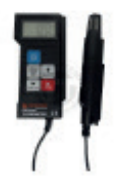

3)

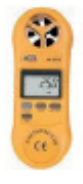

4)

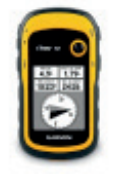

Figura 2 - Aparelhos climatológicos

Fonte: Google imagens, 2014. 1) data logger; 2) termo-higrômetro digital portátil; 3) termoanemômetro digital3 e 4) GPS4

Após a aquisição dos dados em campo os mesmos devem ser sistematizados, organizados em quadros, tabelas e gráficos. A sugestão é que se use a ferramenta Microsoft Excel $^{\circledR}$ e, posteriormente, especializados através da interpolação e representação espacial com o auxílio de softwares. $\mathrm{O}$ mais utilizado neste tipo de trabalho se trata do Surfer for Windows ${ }^{\circledR}$, cuja função é a elaboração de cartogramas de isovalores atribuídas ao campo térmico. Organizadas em escalas de cores para os valores adquiridos demonstram a distribuição espacial da temperatura e da humidade no espaço urbano em todos os episódios, para os três horários de coleta (Imagem 2). Intuindo uma melhor compreensão dos dados junto às análises realizadas em campo, serão obtidas as Cartas Sinóticas de cada episódio para avaliação e correlação das informações (Imagem 3).

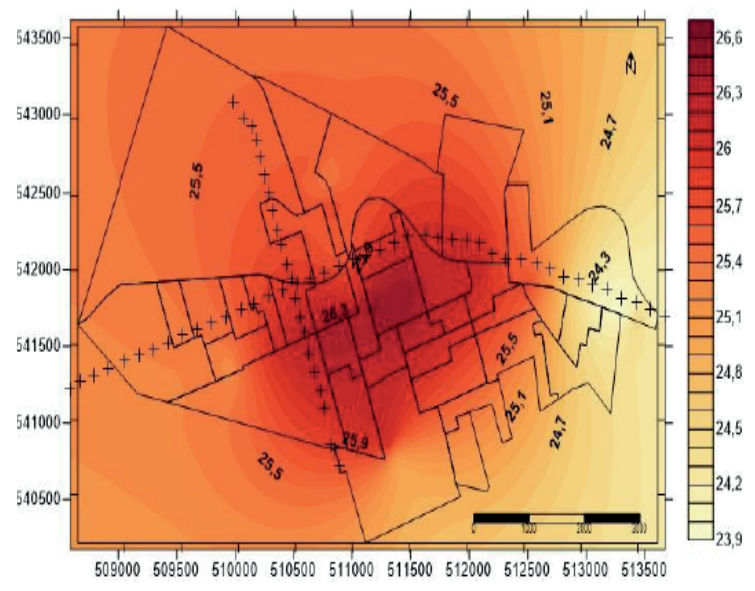

Imagem 2 - Rancharia (SP): cartograma de campo térmico, 2014

Fonte:Teixeira e Amorim, 2014. 


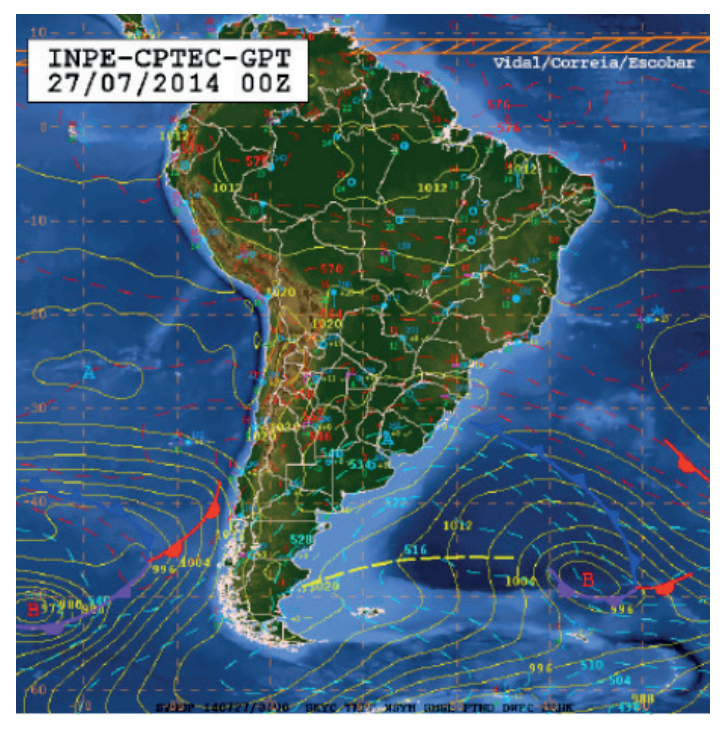

Imagem 3 - Carta Sinótica Jul/2014

Fonte: Instituto de Pesquisas Espaciais (INPE), 2014.

\section{CONSIDERAC̣ÕES FINAIS}

Por fim, diante dos apontamentos é preciso ficar claro que a metodologia aqui apresentada, não é a única para o desenvolvimento de trabalhos ligados ao clima urbano. Porém, a partir dos estudos e das leituras realizadas, a mesma se mostrou eficaz diante dos resultados e objetivos esperados ao final de todo o trabalho.

Pautando-se em análises da área geográfica é possível visualizar que os estudos das variáveis climáticas não são suficientes para transpormos todos os entraves de ordem estrutural da cidade. Porém, este estudo, mesmo de forma pontual, proporciona a identificação da realidade urbana. Nesse sentido, a abordagem da temática faz com que entre em evidência a importância, não só do planejamento do meio físico urbano voltado para as características socioeconômicas, mas, também, do olhar voltado para os elementos naturais e sociais.

Cabe destacar que este trabalho trata de um fragmento do pré-projeto de pesquisa submetido ao Programa de Pós-graduação em Geografia ofertado pelo Instituto de Geografia da Universidade Federal de Goiás/Regional Catalão, e muitas contribuições são esperadas para a execução final do trabalho. Como já mencionado, por se tratar de uma pesquisa em andamento, ainda não é possível apresentar dados concretos sobre a estrutura termohigrométrica do referido recorte de estudo. 


\section{Title: METHODOLOGICAL PROPOSAL FOR ANALYSIS OF THE IMPACT OF GEOGRAPHICAL FACTORS ON CLIMATIC VARIATIONS IN SMALL TOWNS: THE EXAMPLE LAGOA FORMOSA (MG)}

\section{Abstract}

This study aimed to present a methodological proposition for the understanding of the performance of process geographical factors on the urban climate in small towns, taking as an example the city of Lagoa Formosa (MG). For both it was used of ramming that depict the thematic bibliographic, urban climate. The urban Climate System Monteiro (1971), was the basis for the methodological proposal presented. We used the model of transects, furniture which consists in marking and collecting data of temperature and humidity in points scattered throughout the urban site, so embrace, too, the intraurbanos spaces. The data were collected, tabulated and specialised in cartogram form isovalues, showing the reality of the thermal cutout of study. It must be clear that this is one of many methodologies for the analysis of urban climate. Because it is an ongoing research is not yet possible to present concrete data on the termohigrométrica structure of the said study clipping.

Keywords: Urban Climate; Methodological proposition; Lagoa Formosa (MG) 


\section{REFERÊNCIAS}

ARANTES, Otilia, VAINER, Carlos e MARICATO, Ermínia. A cidade do pensamento único: desmanchando consensos. Petrópolis: Vozes, 2000.

ACSELRAD, Henri. Sentidos da Sustentabilidade Urbana. In: A duração das cidades: sustentabilidade e risco nas políticas urbanas. Henri Acselrad (org). Rio de Janeiro: DP\&A, 2001.

CARLOS Ana Fani A.; SOUZA, Marcelo Lopes de; SPOSITO, Maria Encarnação

Beltrão. (Org.). A produção do espaço urbano: agentes e processos, escalas e desafios. São Paulo: Contexto, 2011.

CARLOS, A. F. A. 0 espaço Urbano: Novos escritos sobre a cidade. São Paulo: LABUR, 2007.

CARLOS, A. F. A. A cidade. São Paulo: Contexto, 2008.

CARLOS, A.F. A. A condição espacial. São Paulo: Contexto, 2011. p. 157.

CHAVES, M. R. Descentralização da política Ambiental no Brasil e a Gestão dos Recursos Naturais no

Cerrado Goiano. 2003. 187 f. Tese (Doutorado em Geografia) - Faculdade de Ciências e Tecnologia, Universidade Federal Paulista, Rio Claro, 2003.

CHIZZOTI, A Pesquisa em Ciências humanas e sociais. S.Paulo:Cortez,1995.

CORRÊA, Roberto Lobato. 0 Espaço Urbano. São Paulo: Ática, 1997.

DUARTE, F. Planejamento Urbano. Curitiba: IBPEX, 2007.

GIL, A.C. Como elaborar projetos de pesquisa. 4. ed. São Paulo: Atlas, 2002.

GIL, A.C. Métodos e técnicas de pesquisa social. São Paulo: Atlas, 1999.

GUERRA, Antônio José Texeira; CUNHA, Sandra Baptista. Impactos ambientais urbanos no Brasil. $8^{\circ}$. ed. - Rio de Janeiro: Bertrand Brasil, $2011.418 \mathrm{p}$.

INTSITUTO BRASILEIRO DE GEOGRAFIAEESTATISTICA. Dados Sobre a Cidade de Franca/SP. Disponivel em: http:// www.cidades.ibge.gov.br/xtras/perfil.php?lang=\&codmun=351620\&search=||infogr\%Elficos:-informa\%E7\%F5escompletas Acesso em: 15 de jun. de 2014 ás 14:10

LOPES, Rodrigo. A Cidade Intencional: o planejamento estratégico de cidades. Rio de Janeiro: Mauad, 1998.

LUNA, S. V. Planejamento de pesquisa: uma introdução. São Paulo: EDUC, 2005. 108 p. (Série Trihhas). MALHEIROS, Telma Marques, Política e planejamento ambiental. 3. ed. rev. e atual., 3.reimpr. Rio de Janeiro: Thex, 2009. $480 \mathrm{p}$.

MARICATO, Ermínia. As idéias fora do lugar e o lugar fora das idéias - Planejamento urbano no Brasil. In: A cidade do pensamento único: desmanchando consensos. Petrópolis: Vozes, 2000.

MARICATO, Ermínia. Brasil, cidades: alternativas para a crise urbana: Petrópolis/RJ: Vozes, 2001.

MARICATO, Ermínia. 0 impasse da política urbana no Brasil. Petrópolis/ RJ: Vozes, 2014.

MARICATO, Ermínia. Informalidade urbana no Brasil: a lógica da cidade fraturada. In. São Paulo: relações internacionais e gestão pública. São Paulo: EDUC, 2009.

MILARÉ, Édis. Política Ambiental Brasileira. In: TAUK-TORNISIELO et all. (Orgs.)Análise Ambiental: Estratégias e Aç̃es. São Paulo: T. A. Queiroz / UNESP, 1995.

PALÁCIO DO PLANALTO. Lei no 10.257, de 10 de julho de 2001. Disponível em: <http://www.planalto.gov. 
br/ccivil_03/leis/leis_2001/110257.htm>. Acesso em 5jul. de jul. 2014 ás 20:50.

PORTO-GONCALVES, C. W. Os (des)caminhos do meio ambiente. 14 Ed. São Paulo: Contexto, 2010.

RODRIGUES, Arlete Moyses. Produção do espaço e ambiente urbano. In Sposito, M. Encarnaç̃ão(org). Urbanização e Perspectivas. Unesp. 2001, p. 211-230.

RODRIGUES, Arlete Moyses. A matriz discursiva sobre o "Meio Ambiente" Produção do Espaço Urbano - Agentes, Escalas, Conflitos. In. A Produção do Espaço Urbano. Contexto. 2011, p. 207-230.

RODRIGUES, Arlete Moyses. M. 0 espaço Urbano e as estratégias de planejamento e produção da cidade. In. Planejamento Urbano no Brasil - Conceito, diálogo e práticas. Santa Catarina: Argos, 2008.

RODRIGUES, Arlete Moysés. 2013. Políticas Públicas: FGTS e Planos Diretores. Conteúdos e Significados. Cidades, Rio Claro, v. 9, n. 16, 2012, p. 11-30.

SANTOS, D.P. Considerações acerca do meio ambiente: Compreendendo questões socioambientais contemporâneas. 2013. 61f. Trabalho de Conclusão de Curso (Graduação em Geografia) - Universidade Federal do Triângulo Mineiro, Uberaba. 2013

SANTOS, M. Metamorfoses do espaço habitado. São Paulo: Hucitec, 1988, p. 89. Manual de Geografia Urbana. São Paulo: Hucitec, 2008. . A Urbanização Brasileira. São Paulo: Hucitec, 2002 . A natureza do espaço. $4^{0}$ ed. São Paulo: EDUSP, 1996/2009.

SECRETARIA DE MEIO AMBIENTE DO ESTADO DE SÃO PAULO. Programa Município Verde Azul. Disponível em: http://www.ambiente.sp.gov.br/Municipioverdeazul/o-projeto/Acesso em: 9 de abr. de 2014 ás 12:05 SOUZA, Marcelo Lopes de. ABC do desenvolvimento urbano. Rio de Janeiro: Bertrand Brasil, 2011. SOUZA, Marcelo Lopes de. Mudar a cidade: uma introdução crítica ao planejamento e à gestão urbanos. Rio de Janeiro: Bertrand Brasil, 2013.

SPÓSITO, Eliseu Savério. SPÓSITO, Maria E. B. SOBARZO e SOBARZO, Oscar (orgs). Cidades médias: produção do espaço urbano e regional. São Paulo: Expressão Popular, 2006.

TEXEIRA, Everaldo Celso. 0 papel das políticas públicas no desenvolvimento local na transformação da realidade. Salvador-BA: UFBA, 2002.

TRATA BRASIL. Ranking de Saneamento Básico no Brasil. Disponível em: <http://www.tratabrasil.org.br/ datafiles/uploads/pdfs/Tabela-Ranking.pdf> Acesso em: 20 de set. de 2014.

VASCONCELOS, Pedro de Almeida, CORREAA, Roberto Lobato e PINTAUDI Silvana Maria (Orgs). A cidade Contemporânea: Segregação Espacial. São Paulo: Contexto, 2013.

VILLAC,A, Flávio. Espaço Intra-urbano no Brasil. São Paulo: Studio Nobel/FAPESP, 2001.

VILLAÇ, Flávio. Reflexões Sobre as Cidades Brasileiras. São Paulo: Studio Nobel, 2012.

VITE, Claudete de Castro Silva e Keinert Tânia Margarete Mezzomo. Qualidade de vida, Planejamento e Gestão Urbana: Discussões teórico metodológicas. Rio de Janeiro: Bertrand, 2009. 